\title{
INTERDISCIPLINARIDADE E CONTEXTUALIZAÇÃO NA FORMAÇÃO DOCENTE EM CIÊNCIAS DA NATUREZA SOB A PERSPECTIVA FREIREANA
}

\section{Interdisciplinarity and contextualization in the teacher training for natural sciences under the freirean perspective}

\author{
Ronan Moura Franco* \\ Diana Paula Salomão de Freitas ${ }^{* *}$ \\ Elena Maria Billig Mello***
}

\begin{abstract}
Resumo: Com este trabalho, objetiva-se investigar evidências dos princípios interdisciplinaridade e contextualização em registros escritos produzidos durante a formação inicial de um professor formado em um curso de Ciências da Natureza. Registros escritos a partir das vivências em práticas educativas, pertinentes à reflexão sobre a formação, compõem o corpus de análise, produzidos em articulação com características do estudo de caso, analisados por Análise Textual Discursiva e discutidos sob a alcunha do referencial de Paulo Freire. Os resultados evidenciam a presença dos princípios investigados em práticas que promoveram a vivência e reflexão dos princípios, no sentido de permitir uma compreensão de como estes princípios constituíram o professor investigado. Com a realização do trabalho, percebe-se que a pedagogia freireana contribui para a compreensão da indissociação dos princípios investigados e subsidia a problematização da prática formativa, considerando o processo reflexivo de ensinar-aprender em uma perspectiva interdisciplinar, contextualizada e emancipatória.
\end{abstract}

Palavras-chave: Interdisciplinaridade. Ciências da natureza. Pedagogia freireana.

Abstract: Through this paper, it is aimed to investigate the evidences behind the principles of interdisciplinarity and contextualization by written records made during the initial formation of a teacher graduated in the Natural Sciences course. Records written from the experiences and educational practices, relevant for the reflection under the academic training, making up the analysis corpus, done in articulation with characteristics from the case study, and analysed by the Discursive Textual Analysis and discussed under the sobriquet of Paulo Freire's referential. The results point to the presence of the investigated principles, in the sense of allowing a

\footnotetext{
* Doutorando em Educação em Ciências: química da vida e saúde pela Universidade Federal do Pampa. Professor de Ciências na Escola Municipal de Ensino Fundamental Moacyr Ramos Martins, Professor de Física no Colégio Marista Sant'Ana. orcid.org/0000-0001-7237-2258. E-mail: rmourafranco@gmail.com.

** Doutora em Educação em Ciências: química da vida e saúde pela Universidade Federal do Rio Grande. Professora adjunta da Universidade Federal do Pampa, professora permanente dos Programas de Pós-graduação em Ensino e Educação em Ciências: química da vida e saúde. orcid.org/0000-0001-6944-2219. E-mail: disalomao@gmail.com.

**** Doutora em Educação pela Universidade Federal do Rio Grande do Sul. Professora associada da Universidade Federal do Pampa, professora permanente dos Programa de Pós-graduação em Ensino e curso de especialização em Neurociência aplicada à Educação da Universidade Federal do Pampa. orcid.org/0000-0003-0366-3021. Email: profelena@gmail.com.
} 
comprehension on how this said principles constituted the investigated teacher. With the completion of the work, it is clear that freire's pedagogy contributes to the understanding of the indissociation of the investigated principles and supports the problematization of training practice, considering the reflective process of teaching-learning in an interdisciplinary, contextualized and emancipatory perspective.

Keywords: Interdisciplinarity. Natural sciences. Freirean pedagogy.

\section{Introdução}

Diante do atual cenário sociopolítico do Brasil, a educação brasileira encontra-se em constante tensionamento. Com isso, emerge a necessidade de reforçarmos o papel do professor como sujeito indispensável nas transformações educacionais. Para tanto, as práticas educativas de formação docente necessitam ser refletidas, no sentido de se fortalecer e inovar a ação docente, adaptando-se às exigências e provocando as mudanças dos modos de ensinar-aprender. Trazemos à luz, nesta pesquisa, a formação docente em Ciências da Natureza na direção de uma educação pública e democrática.

A questão de pesquisa que conduziu este trabalho pode ser compreendida como uma das formas de contribuir para a qualificação das práticas educativas de formação docente em Ciências da Natureza: 'Como se evidenciam os princípios interdisciplinaridade e contextualização em registros escritos produzidos durante a formação inicial de um professor licenciado em Ciências da Natureza e que atua na Educação Básica?' Como forma de responder a esse questionamento, objetivamos investigar evidências dos princípios da interdisciplinaridade e da contextualização em registros escritos produzidos durante a formação inicial de um professor licenciado em Ciências da Natureza.

A ação docente é vista como processo inacabado, em que, nesse momento de formação, destaca-se o papel fundamental da reflexão sobre a própria atuação, sendo que o ato de refletir e repensar a ação docente constitui-se como um instrumento que dinamizará a relação entre teoria e prática. Refletir para desencadear processos e ações transformadoras de si, dos sujeitos e do contexto em que estão inseridos. Os processos de reflexão na ação caracterizam-se como um movimento dialógico e dialético; assim, é vivo de trocas e reações, gerando novos saberes sobre a forma com que se atua em sala de aula. O fato de o professor ser reflexivo durante sua formação e atuação conduz à compreensão das dificuldades, orientando suas futuras ações na medida em que se descobrem soluções para as situações problemas e/ou contradições que se apresentam no decorrer da sua trajetória (FREIRE, 2002; PÉREZ-GÓMEZ, 1999).

Para desenvolvermos este trabalho, Paulo Freire foi a opção teórico-epistemológica assumida, que se fundamenta na vertente transformadora da educação, balizada pelos princípios de participação, criticidade, amorosidade, rigorosidade, humanização, dialogicidade, autonomia, entre outros. Freire assume que: “[...] além de um ato de conhecimento, a educação é também um ato político. É por isso que não há pedagogia neutra" (FREIRE, 2002, p. 25). Com isso, entendemos que a formação de professores leva em conta aspectos acadêmicoprofissionais no sentido de que "[...] aprender e ensinar fazem parte da existência humana, histórica e social [...]” (FREIRE, 2001, p. 19).

Ao falarmos do princípio da interdisciplinaridade, assumimos que esse propõe a reciprocidade entre as disciplinas ou áreas do conhecimento, representando, além do encontro entre disciplinas, o grande encontro daqueles que habitam o território das disciplinas [componentes curriculares] e que desejam ultrapassá-lo, em direção a um conhecimento que possa fazer sentido para a história da humanidade (JAPIASSÚ, 1976). A interdisciplinaridade 
visa garantir a construção de um conhecimento globalizante, rompendo as fronteiras dos componentes curriculares. Para isso, integrar conteúdos não seria suficiente. Segundo Morin (2000; 2005), as disciplinas [componentes curriculares] têm sua origem na tentativa de organizar o conhecimento e o problema é "[...] encontrar a via de articulação entre as ciências, pois cada área apresenta linguagens e códigos próprios, mas também conceitos fundamentais que não podem ser simplesmente transferidos de uma para outra" (MORIN, 2000, p. 113).

Aproximamo-nos dos argumentos de Morin (2005) ao afirmar que somente um pensamento complexo, pela sua multiplicidade de fatores constituintes e uno em sua totalidade, é capaz de conduzir os processos de transformações das práticas de ensino na direção da interdisciplinaridade do conhecimento produzido. A interdisciplinaridade será, então, o meio articulador do processo ensino-aprendizagem, assumindo-se a partir de uma atitude que se estabelece no encontro dialógico dos sujeitos que ocupam o território das disciplinas (FAZENDA, 1979). Além disso, a interdisciplinaridade deve ser compreendida como pressuposto na organização curricular, bem como fundamento para as metodologias do ensino (GADOTTI, 2004; JAPIASSÚ, 1976).

Nessa perspectiva, transcorrendo os argumentos de Freire (2011), em que o conhecimento é concebido como um processo de (re)construção do mundo, a interdisciplinaridade propicia uma visão mais ampla da realidade. Para isso, atingir a totalidade surge como pressuposto fundamental para a compreensão da realidade, que não será compreendida se captada de forma fragmentada. Freire ainda afirma que a questão fundamental reside na falta de uma compreensão crítica da totalidade pelas pessoas, pois "[...] captando-a em pedaços nos quais não reconhecem a interação constituinte da mesma totalidade, não podem conhecê-la" (FREIRE, 2011, p. 111).

A contextualização é entendida enquanto a busca por significados do conhecimento a partir de contextos do mundo ou da sociedade em geral. Consiste em levar o aluno a compreender a relevância de aplicar o conhecimento aprendido para entender os fatos e fenômenos que o cercam (MORIN, 2000, 2005). Nesse sentido, o que se propõe é identificar situações-problema que surgem como manifestações das contradições envolvidas nos contextos do trabalho educativo, que se apresentam como desafios para compreensão da realidade - temas que poderão ser trabalhados nas aulas. A educação contextualizada precisa ser compreendida como um campo de transgressões, não estando limitada somente ao contexto, mas deste partindo e a ele chegando (DELIZOICOV; ANGOTTI; PERNAMBUCO, 2004).

Contrariando o ensino descontextualizado, a contextualização expressa-se no conhecimento presente na vida do aluno, que possibilita a resolução de problemas e a construção de uma visão de mundo mais complexa. É preciso que as informações estejam situadas em seu contexto para que adquiram sentido e para que esse seja importante para a vida dos alunos. Buscar o significado do conhecimento a partir do contexto do mundo ou da sociedade em geral é levar o aluno a compreender a relevância e aplicar o conhecimento para entender os fenômenos e processos (MORIN, 2000; 2005).

O pensamento que promove o ensino contextualizado deve estar em constante busca pela inseparabilidade e pelas inter-relações entre o fenômeno e seu contexto. Contextualizar é um fazer constante do professor em relação ao processo de ensinar e aprender, de criar condições para que tanto ele como o aluno experimentem a curiosidade e o encantamento da descoberta, bem como a satisfação de construir o conhecimento com autonomia (FREIRE, 2011).

O ensino contextualizado necessita da construção de momentos que, na prática pedagógica, favoreçam: a) a expressão do saber prévio dos participantes do processo educativo; 
b) a organização das situações que proporcionem um ambiente democrático, em que todos ensinem e aprendam; c) a abordagem de objetos ou temas de situações em relação com o meio em que estão inseridos (DELIZOICOV; ANGOTTI; PERNAMBUCO, 2004; FREIRE, 2011; MORIN, 2000; 2005).

Freire afirma que é "[...] a partir da situação presente, existencial, concreta, refletindo o conjunto de aspirações do povo, que poderemos organizar o conteúdo programático da educação" (FREIRE, 2011, p. 100). Na concepção do autor, contextualizar é, portanto, refletir a partir da realidade, compreendendo a vida e os processos de construção e desenvolvimento da sociedade em seus diversos aspectos.

O princípio da contextualização aproxima-se do que Freire diz ser a problematização das situações existenciais, pois não basta relacionar o conteúdo com a realidade, e sim identificar as situações-problema da realidade sobre as quais os sujeitos que aprendem podem transformá-las. Freire nos diz que, enquanto educadores, no desenvolvimento da nossa prática, devemos "[...] propor ao povo, através de certas contradições básicas, sua situação existencial, concreta, presente, como problema que, por sua vez, o desafia e, assim, lhe exige resposta, não só no nível intelectual, mas no nível da ação" (FREIRE, 2011, p. 100). Sobre a capacidade de compreensão da realidade de que a educação é capaz, o autor afirma que: "O homem não pode participar ativamente na história, na sociedade, na transformação da realidade se não for ajudado a tomar consciência da realidade e da sua própria capacidade para transformar" (FREIRE, 1977, p. 48).

Uma das condições para o ensino contextualizado é o (re)conhecimento dos sujeitos do processo de ensino-aprendizagem, de suas experiências e de seu entendimento do mundo. Entendimento esse que possibilita a criticidade na leitura das situações, em que o sujeito ultrapasse a consciência ingênua e alcance a consciência crítica. Além disso, perceber contradições é difícil. O processo também é esta busca por contradições do que acontece, como acontece, para quem acontece, por que acontece.

Com o propósito de aprofundarmos a reflexão sobre os princípios interdisciplinaridade e contextualização, estruturamos esta escrita em quatro partes que se complementam. Após essa introdução, é apresentado o percurso teórico-metodológico a partir de um estudo de caso. $\mathrm{Na}$ sequência, apresentamos a análise realizada das unidades de significados dos registros escritos de práticas educativas vivenciadas no curso de Ciências da Natureza por um professor pesquisador, com ênfase nesses princípios. Por último, apresentamos as considerações finais, com a sistematização das argumentações construídas pertinentes à formação docente.

\section{Percurso metodológico}

A presente pesquisa caracteriza-se como estudo de caso, com abordagem qualitativa, que analisou registros escritos decorrentes de componentes curriculares (CC) da trajetória acadêmica de um professor pesquisador no curso de graduação em Ciências da Natureza.

O estudo de caso é entendido como uma análise detalhada de um caso específico, supondo que é possível o conhecimento de um fenômeno a partir do estudo minucioso de um único caso. Autores como Franco (1990) e Chizzotti (2006) defendem que o caso pode ser uma instituição, uma escola, um currículo, em evento, um grupo, e até mesmo uma pessoa, como é o caso desta pesquisa, que investiga evidências dos princípios interdisciplinaridade e contextualização em registros escritos produzidos durante a formação inicial de um licenciado em Ciências da Natureza, hoje atuando na Educação Básica. O caso em si pode ser considerado como uma unidade que representa um todo, mais amplo e complexo, e, portanto, é capaz de 
sustentar proposições acerca da realidade desse todo. Segundo os autores mencionados, esse tipo de metodologia de pesquisa qualitativa requer de quem pesquisa, entre outras capacidades, a coerência entre observação e análise sistemática dos dados investigados (CHIZZOTTI, 2006; FRANCO, 1990).

Durante a trajetória formativa do professor, alguns CC propiciaram mais intensamente a reflexão sobre a formação do professor, expressas em trabalhos organizados para apresentação de seminários, relatórios, resenha, portfólio, projeto de intervenção e produção de artigos. Estas diferentes atividades vivenciadas pelo professor condicionaram a produção dos registros em documentos escritos, e a reflexão sobre este material ressignificou os saberes sobre a constituição do próprio professor.

Inicialmente, a análise exploratória identificou os $\mathrm{CC}$ do Curso de Ciências da Natureza que propiciaram práticas educativas com registro de reflexão sobre a formação docente. $\mathrm{O}$ referido Curso, oferecido em uma universidade pública situada na mesorregião metade sul do Rio Grande do Sul, Brasil, oferta sessenta CC, distribuídos em nove semestres (PPC, 2013). Foram selecionados quatorze $\mathrm{CC}$, por apresentarem atividades que possibilitaram a reflexão sobre a formação, com evidências nos princípios formativos interdisciplinaridade e contextualização, conforme pode ser observado no Quadro 1. Esses CC compuseram o corpus de análise. Foram numerados e classificados por tipo de registro escrito (RE), que foram analisados e receberam um código.

Quadro 1 - Corpus de análise da pesquisa: classificação e codificação dos componentes curriculares por tipo de registro escrito.

\begin{tabular}{|c|c|c|c|}
\hline Componente Curricular (CC) & $\mathbf{N}^{\circ} \mathbf{C C}$ & $\begin{array}{l}\text { Código Registro } \\
\text { Escrito (RE) }\end{array}$ & Tipo de registro escrito \\
\hline Introdução às Ciências da Natureza & 1 & RE1 & Relatório \\
\hline $\begin{array}{l}\text { Universo em Evolução e Evolução da } \\
\text { Vida na Terra }\end{array}$ & 2 & RE2 & Relatório \\
\hline Filosofia e História da Educação & 3 & RE3 & Resenha \\
\hline Ecossistemas da Terra & 4 & RE4 & Relatório \\
\hline Leitura e Produção Textual & 5 & RE5 & Portfólio \\
\hline Experimentação II & 6 & RE6 & Relatório \\
\hline Diversidade de Vida II & 7 & RE7 & $\begin{array}{l}\text { Trabalho organizado para } \\
\text { apresentação de seminário }\end{array}$ \\
\hline Educação e Saúde & 8 & RE8 & Relatório \\
\hline Diversidade Vegetal II & 9 & RE9 & $\begin{array}{l}\text { Trabalho organizado para } \\
\text { apresentação de seminário }\end{array}$ \\
\hline $\begin{array}{c}\text { Corpo, Gênero, Sexualidade e } \\
\text { Relações Étnico-Raciais na Educação }\end{array}$ & 10 & RE10 & Produção de artigo \\
\hline Som, Imagem e Informação & 11 & RE11 & $\begin{array}{l}\text { Trabalho organizado para } \\
\text { apresentação de seminários }\end{array}$ \\
\hline Estágio Supervisionado I & 12 & RE12 & Unidade Didática \\
\hline Educação Ambiental & 13 & RE13 & $\begin{array}{l}\text { Proposta de projeto de } \\
\text { intervenção }\end{array}$ \\
\hline Estágio Supervisionado II & 14 & RE14 & Relatório \\
\hline
\end{tabular}

Fonte: autoria própria.

A análise dos registros escritos foi realizada por meio da metodologia de Análise Textual Discursiva (ATD), proposta por Moraes e Galiazzi (2011). A ATD consiste em um processo integrado de análise e síntese, e tem por objetivo desenvolver uma leitura rigorosa e 
aprofundada de conjuntos de materiais textuais, descrevendo e interpretando no sentido de "[...] atingir uma compreensão mais complexa dos fenômenos e dos discursos" (MORAES; GALIAZZI, 2011, p. 114).

A análise envolveu os seguintes procedimentos investigativos: a) leitura dos registros (separação destes por $\mathrm{CC}$ e produção de fichas de leitura dos referenciais teóricos que fundamentaram a pesquisa); b) desconstrução dos textos (fragmentação dos registros em excertos que evidenciaram a reflexão sobre a formação, articulada aos princípios formativos interdisciplinaridade e contextualização); c) unitarização dos registros (codificação dos excertos, identificados como unidades de significado, de acordo com a classificação dos CC e do tipo de registro produzido, visualizados no Quadro 1); d) categorização das unidades de significado (processo de agrupamentos de unidades de significado com sentidos semelhantes, categorizadas conforme os princípios interdisciplinaridade e contextualização, estabelecidos enquanto categorias a priori, ainda que cientes de que outras categorias poderiam emergir no processo análise); e) construção do metatexto (elaboração de texto resultante dos procedimentos de análise), o qual é constituído pela discussão teórico-reflexiva das categorias definidas $a$ priori, que são os princípios formativos da interdisciplinaridade e da contextualização e que apresentamos a seguir.

\section{Análise e discussão dos resultados}

\subsection{Práticas educativas e o princípio da interdisciplinaridade}

Para iniciar a análise das práticas educativas (PE) referentes ao princípio da interdisciplinaridade, revisitamos o que já afirmamos anteriormente: que a interdisciplinaridade consiste em interação entre áreas do conhecimento e de saberes que se engendram, pressupondo uma organização dialógica do conhecimento, em um processo de articulação das ações disciplinares orientadas por um interesse comum (FAZENDA, 1979; 1991; JAPIASSÚ, 1976; MORIN, 2005; SANTOMÉ, 1998).

$\mathrm{Na}$ análise realizada, a partir do corpus da pesquisa (Quadro 1), destacamos que o CC Experimentação II, ao propor práticas pedagógicas experimentais, criou espaços de reflexão sobre a dinâmica e a organização das escolas nas áreas do saber referentes ao estudo das Ciências da Natureza na Educação Básica (PPC, 2013, p. 112). Como parte da discussão, destacamos a unidade de significado subsequente, sobre o estudo do objeto de conhecimento fotossíntese, observada nas aulas:

[...] o estudo interdisciplinar da fotossíntese possibilita uma compreensão mais complexa deste processo, em que, conhecendo os aspectos químicos, físicos e biológicos envolvidos, a construção do conhecimento científico acontece de maneira ampla, possibilitando a interpretação e leitura do mundo e seus acontecimentos (RE6.1).

Esse trecho evidenciou uma premissa para a construção do pensamento interdisciplinar, entendido aqui como abordagem teórico-metodológica, em que a ênfase incidiu sobre o trabalho de integração das diferentes áreas do conhecimento, no caso, por meio de um experimento e das discussões decorrentes da proposta, possibilitando um real trabalho de cooperação, aberto ao diálogo e ao planejamento. 

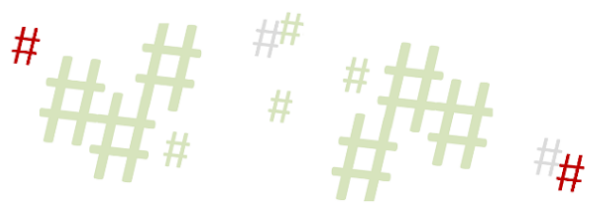

Percebemos que a proposição de trabalhos interdisciplinares colaborou para o desenvolvimento de atitudes interdisciplinares no professor pesquisador foco deste estudo. Segundo Santomé (1998), as práticas interdisciplinares exigem do professor uma postura diferenciada. Planejar, desenvolver e fazer um acompanhamento contínuo do trabalho interdisciplinar pressupõe uma reflexão permanente, pois, assim como somos formados em uma educação pautada pela fragmentação dos saberes, acabamos por ensinar de maneira fragmentada. A proposição de um ensino fundamentado no princípio da interdisciplinaridade implica, simultaneamente, mudanças na formação de professores em relação à metodologia e à relação pedagógica baseada na transmissão do saber a partir de um modelo hierárquico-linear, para proposição de uma relação pedagógica dialógica e democrática. Para tanto, reafirmamos a importância de se estabelecer uma postura interdisciplinar, buscando o envolvimento, o compromisso e a reciprocidade diante do conhecimento, que é desafio para todos os envolvidos na/com a educação. Desse modo, como escreveu Fazenda (1991, p. 18), “[...] o que caracteriza a atitude interdisciplinar é a ousadia da busca, da pesquisa: é a transformação da insegurança num exercício do pensar, num construir".

No decorrer da trajetória de formação do professor, outros CC promoveram meios para o desenvolvimento dessa atitude interdisciplinar com a proposição de conexões e inter-relações de duas ou mais áreas do conhecimento. Assumimos, então, que não basta apenas que o currículo seja formulado de forma integrada; é preciso que essa integração seja vivenciada, como no CC Diversidade de Vida II. No contexto da proposição do referido CC, mesmo com enfoque no estudo referente à Biologia, deu-se a necessidade de discussões e o estabelecimento de relações com outras áreas do conhecimento que mobilizaram para a vivência interdisciplinar. Concernente ao estudo dos conteúdos da Biologia, o CC de Diversidade de Vida II provocou a desacomodação do professor pesquisador, quando promoveu a busca de conhecimento para além dos limites dos conteúdos específicos, demandando a necessidade de se romper com a tendência fragmentada do conhecimento, que se justificou pela compreensão da importância da interação instituída entre as diferentes áreas do saber das Ciências da Natureza. Isso é evidenciado na unidade de significado a seguir:

\footnotetext{
Os trabalhos interdisciplinares foram de livre escolha e diversos assuntos foram abordados e relacionados como, por exemplo: o sonar de morcegos e golfinhos, a respiração dos peixes e suas relações químicas e físicas. Este trabalho possibilitou a abordagem interdisciplinar dos conteúdos, possibilitando pesquisas que relacionavam os conteúdos da área das Ciências da Natureza, propósito esse do curso em que estamos inseridos (RE7.1).
}

A interação entre as áreas do conhecimento é muito mais do que o ato de usar saberes isolados de uma área para representar um conteúdo. Há a necessidade de buscarmos a interação entres diferentes áreas do conhecimento, pois, essencialmente, todo conhecimento está interligado. Como exemplo, a prática acima apresentada, partindo dos conteúdos da Biologia, buscou relações com conteúdos da Química e da Física, considerando as especificidades que integram seus estudos, como os cálculos matemáticos e as fórmulas químicas presentes. Nesse sentido, Delizoicov, Angotti e Pernambuco afirmam:

Como se fosse possível pensar em Ciências da Natureza sem um domínio de suas linguagens, matemáticas ou explicativas. Ou como se essas linguagens - por exemplo, leitura, escrita e matemática - existissem por si só, sem precisarem adquirir um significado de expressão ou comunicação e uma ideia ou conhecimento (DELIZOCOV; ANGOTTI; PERNAMBUCO, 2004, p. 125). 
A interdisciplinaridade permite reconhecer não só o diálogo entre os $\mathrm{CC}$, mas também a conscientização sobre o sentido da presença do ser humano no mundo. Dessa maneira, o diálogo, que se estabelece na busca da interdisciplinaridade, vai nos desafiando a pensar a história social como uma experiência, que é igualmente social, revelando a necessidade de superarmos certos saberes que, isolados, não são capazes de explicar os fatos (FAZENDA, 2008; FREIRE, 2002).

O CC Som, Imagem e Informação oportunizou o exercício de uma prática educativa que buscou promover o ensino interdisciplinar, em que os acadêmicos escolhiam temas relacionados ao estudo da Física, assumindo os papéis de educadores/as, planejando e construindo uma "aula recorte". Trazemos a reflexão que aborda a importância da realização dessa prática educativa para a formação docente:

Consideramos que este trabalho colaborou na formação de professores, propiciando práticas que envolvam a contextualização e a interdisciplinaridade, a qual exige interação entre as disciplinas e os sujeitos envolvidos. É fundamental, para o exercício da prática docente, que um educador possibilite situações dinâmicas para o efetivo ensino dos conteúdos, despertando nos alunos o interesse e a relação com seu cotidiano (RE11.2).

A oportunidade de vivenciar experiências como essa nos torna capazes de intervir no processo de aprendizagem - o que concebemos enquanto uma tarefa complexa e geradora de novos saberes. Dessa maneira, dialogando com Freire $(2002 ; 2011)$, também não nos parece possível - nem aceitável - a posição ingênua e neutra de quem estuda o conteúdo específico, seja o profissional físico, seja o biólogo, seja o sociólogo, seja o matemático. Não estamos no mundo interagindo e experienciando com os outros de forma neutra.

Consideramos pertinente a afirmação de Freire:

Tão importante quanto ele, o ensino dos conteúdos, é o meu testemunho ético ao ensiná-los. É a decência com que o faço. É a preparação científica revelada sem arrogância, pelo contrário, com humildade. É o respeito jamais negado ao educando, a seu saber de experiência feito que busco superar com ele. Tão importante quanto o ensino dos conteúdos é a minha coerência entre o que digo, o que escrevo e o que faço (FREIRE, 2002, p. 64).

As abordagens interdisciplinares requerem a atenção criteriosa da instituição escolar, pois revelam as perspectivas metodológicas que orientam as práticas pedagógicas dos educadores, tornando-se estratégias que possibilitam a construção do conhecimento de quem estuda.

Durante a graduação, o CC Estágio supervisionado I, essencialmente, possibilitou a inserção do professor durante sua formação inicial na escola, a fim de que o mesmo vivenciasse o espaço profissional por meio do acompanhamento do professor regente do CC de Ciências Naturais no Ensino Fundamental. Para tanto, foi elaborada uma proposta didática que foi aplicada no CC Estágio supervisionado II (PPC, 2013, p. 194). A proposta didática compreendeu o estudo do corpo humano, focada no sistema genital, abordando a sexualidade, enquanto um tema com possível viés transversal, como podemos verificar no seguinte registro: 
Esta proposta didática buscou estruturar o desenvolvimento de um trabalho que relacione os conteúdos específicos do Sistema Genital, problematizando a Diversidade no contexto da escola. A Unidade foi planejada de maneira que os conteúdos conceituais estejam intrínsecos nas dinâmicas propostas, visando à construção do conhecimento, a partir dos conteúdos procedimentais utilizados (RE12.1).

Nesse sentido, ao trazermos uma prática com potencial de ser abordada de forma transversal, estamos considerando que o estudo com projetos temáticos foi pertinente, pois envolveu várias áreas do conhecimento, o que, se aliado a uma predisposição dos sujeitos envolvidos no processo pedagógico, torna-se um exercício efetivo do princípio da interdisciplinaridade.

Nesse caso, o conhecimento constitutivo de diferentes CC caracterizou-se interdisciplinarmente por meio da ação didático-pedagógica proposta por projetos temáticos, existindo o diálogo do $\mathrm{CC}$ com outros conhecimentos e com o conhecimento dos sujeitos envolvidos. A prática de planejamento citada permitiu que as discussões decorrentes do seu desenvolvimento não estivessem limitadas aos conteúdos da temática trabalhada, fazendo parte da importância dos conteúdos com a qualidade crítico-epistemológica com que o educador posiciona-se diante deles. Ao encontro desse argumento, Freire (2001, p. 85-86) afirma que: "[...] por mais fundamentais que sejam os conteúdos, a sua importância efetiva não reside apenas neles, mas na maneira como sejam apreendidos pelos educandos e incorporados à sua prática”.

Procuramos evidenciar como determinadas práticas educativas contribuíram para o rompimento de uma visão fragmentada dos conhecimentos estudados e, dessa forma, para a integração do conhecimento construído, utilizando-se de fundamentos das teorias que abordam a interdisciplinaridade e as concepções pedagógicas de Freire. Além disso, verificamos que compreender a totalidade torna-se requisito para a compreensão crítica da realidade.

Na perspectiva que Freire apresenta-nos, compreender a totalidade é experienciar a realidade não apenas para nos adaptarmos, mas "[...] sobretudo para transformar a realidade, para nela intervir, recriando-a" (FREIRE, 2002, p. 69). Ao afirmarmos isso, estamos constatando que, para adquirir significado, o conhecimento deve ser contextualizado, e é sobre as contribuições do princípio da contextualização nas práticas educativas de formação do professor que discutiremos no item a seguir.

\subsection{O princípio da contextualização nas práticas educativas}

Neste movimento de pesquisa, reafirmamos o entendimento, já exposto, que assumimos de contextualização, entendida enquanto a relação do conhecimento com a realidade, buscando a significação desse nos contextos em que conhecimento e realidade estão inseridos. Ainda, a contextualização preconiza que o conhecimento parte da realidade e deve a essa retornar, num movimento dialético (DELIZOICOV; ANGOTI; PERNAMBUCO, 2004; FREIRE, 2001; 2002; 2011; MORIN, 2010).

Evidenciamos algumas unidades de significado dos registros escritos, construídos a partir de práticas que problematizaram e discutiram a importância do princípio de contextualização presente na formação docente do professor pesquisador.

No CC Leitura e Produção Textual, a prática analisada refere-se à construção de um portfólio. Essa atividade foi proposta como maneira de registrar, de forma reflexiva, 
experiências pertinentes à formação, exercitando as habilidades de leitura e escrita. O portfólio configurou-se como instrumento individual de construção recursiva de textos, mediado pela leitura crítica do coletivo da sala de aula, sendo dividido em quatro seções, dentre elas o "Registro dos Sentidos". Nessa seção, foram evidenciadas, pelas unidades de sentidos, informações ou situações que sensibilizaram o professor investigado.

A unidade de significado, oriunda da análise do portfólio, relata o contato com uma família carente, que vivia em condições precárias no entorno da escola de atuação. A atividade de reconhecimento desse entorno foi realizada enquanto o acadêmico fora bolsista do subprojeto Ciências da Natureza "Temas Transversais", que integrou o Programa Institucional de Bolsa Iniciação à Docência (PIBID). A unidade de significado expressa o seguinte: "Ao conhecermos sua realidade logo nos toma um sentimento de comoção, pena. Enquanto falavam, eu mal escutava o que diziam, apenas me colocava no lugar daquelas pessoas, pensava na capacidade do ser humano de aguentar determinadas situações” (RE5.4).

O registro a seguir evidencia a conscientização sobre o contexto social, quando ressaltamos a importância do ensino voltado para a realidade, que leva a querer transformar as situações contraditórias, injustas e opressoras:

\begin{abstract}
Como educador em formação e justamente realizando um trabalho de percepção da realidade, me senti no dever de tentar mudar aquela realidade, ou promover naquelas pessoas o sentimento de transformação. Escrevendo este relato, acredito que eu já esteja fazendo isso, pois não passou despercebida toda situação que encontramos. O sentimento que me incomoda é alimentado por uma vontade de fazer com que alguma coisa mude, e que seja por mim, para poder ajudar as pessoas de alguma forma (RE5.5).
\end{abstract}

Consideramos pertinente destacar que a atividade cooperou para a inserção direta do professor pesquisador no contexto de atuação, percebendo contradições de forma dialógica. Isso mostrou que não basta relacionarmos conteúdos com a realidade. Para compreensão mais integral das relações desse contexto material, devemos vivenciá-lo, pois "[...] não é possível transformar a realidade concreta na realidade imaginária” (FREIRE, 2011, p. 53).

Assim, entendemos que contextualizar é manter uma postura frente ao ensino o tempo todo, criando condições para que o aprendente experimente o contexto, de forma curiosa e investigadora, promovendo o encantamento da descoberta e a satisfação de construir o conhecimento com autonomia (FREIRE, 2001; 2002; 2011). Em conformidade com o exposto, coadunamo-nos com Freire em relação à "[...] a inserção lúcida na realidade, na situação histórica, que a levou à crítica desta mesma situação e ao ímpeto de transformá-la" (FREIRE, 2011, p. 74-75).

Retomando as unidades supracitadas, podemos compreender que um ensino contextualizado não permite apenas olhar, mas ajuda no desvelamento para melhor compreender e transformar as situações de contradições e injustiças. Nesse sentido, os conteúdos curriculares específicos tornam-se elos entre o que se vivencia e o que está além do que se compreende.

A relação dos conteúdos com o contexto conduz ao processo de (re)conhecimento da realidade. Para Freire, “[...] é exatamente esta unidade dialética que gera um atuar e um pensar certos na e sobre a realidade para transformá-la" (2011, p. 35). 
Outro CC que possibilitou o conhecimento e a inserção na realidade, que propôs trabalhos a partir da problematização, foi o CC Educação e Saúde. Este CC teve como finalidade inserir as discussões acerca da inter-relação entre educação e saúde, procurando sensibilizar a partir do desenvolvimento de atividades promotoras da saúde na comunidade escolar, com a finalidade de melhorar o aprendizado e a qualidade de vida. O CC ainda objetivou compreender, de uma maneira ampla e abrangente, a importância da saúde ambiental na saúde das coletividades, entendendo a articulação existente entre promoção, saneamento e prevenção de saúde (PPC, 2013, p. 177).

Assim, o CC Educação e Saúde possibilitou o desenvolvimento de ações contextualizadas, visto que desenvolveu atividades junto à comunidade, articulando questões que envolvessem meio ambiente, saneamento básico, saúde coletiva, entre outras. A atividade proposta consistiu na visita ao Lixão do Município, para que o professor pesquisador conhecesse o local, os impactos ambientais dos resíduos no local e, principalmente, as pessoas que ali trabalhavam e viviam, percebendo e problematizando as contradições sociais a partir da forma de vida naquelas condições. Após a visita, foi produzido um registro escrito, em que se destaca a seguinte unidade de significado:

\begin{abstract}
A escola torna-se uma aliada forte nesse contexto de educação e incentivo das práticas de reconhecimento do município, pois nós, enquanto futuros educadores em Ciências da Natureza, podemos, a partir de estudos como este, possibilitar que os alunos e as alunas sejam transformadores da atual realidade a partir de suas ações, em busca de uma sociedade justa (RE8.1).
\end{abstract}

A partir do exposto, entendemos que a escola tem, diante de si, o desafio de sua própria recriação, pois tudo o que a ela se refere pode se constituir como invenção. Os rituais escolares são invenções de um determinado contexto sociocultural em movimento, sendo valorizadas as diferenças manifestadas pelos sujeitos do processo educativo, nos mais diversos segmentos, respeitando seus tempos e seus contextos socioculturais (BRASIL, 2010).

Freire (1978) manifestou que o ser humano, da mesma forma que transforma a realidade em que vive, com o mundo e com os outros, transforma-se. Contudo, não somos capazes de captar o dado da realidade, o fenômeno, a situação-problema de maneira pura. Na captação, juntamente com o problema, com o fenômeno, captam-se também os nexos causais. $\mathrm{O}$ autor referido apresenta alguns questionamentos sobre a importância de discutirmos a realidade em sala de aula:

\footnotetext{
Por que não discutir com os alunos a realidade concreta a que se deva associar a disciplina cujo conteúdo se ensina, a realidade agressiva em que a violência é a constante e a convivência das pessoas é muito maior com a morte do que com a vida? Por que não estabelecer uma necessária 'intimidade' entre os saberes curriculares fundamentais aos alunos e a experiência social que eles têm como indivíduos? Por que não discutir as implicações políticas e ideológicas de tal descaso dos dominantes pelas áreas pobres da cidade? (FREIRE, 2002, p. 17).
}

Percorrendo os questionamentos de Freire, relacionando-os com a unidade de significado RE8.1, refletimos que, independentemente do contexto em que a escola está inserida, é preponderante (re)conhecermos sua realidade para que os sujeitos reconheçam-se e saibam de que forma podem atuar sobre ela para transformá-la. Os espaços educativos 
inscrevem-se em bairros e localidades que compreendem a totalidade de cada cidade. Sobre isso, Freire (2001) afirmou que:

\begin{abstract}
A Cidade se faz educativa pela necessidade de educar, de aprender, de ensinar, de conhecer, de criar, de sonhar, de imaginar que todos nós, mulheres e homens, impregnamos seus campos, suas montanhas, seus vales, seus rios, impregnamos suas ruas, suas praças, suas fontes, suas casas, seus edifícios, deixando em tudo o selo de certo tempo, o estilo, o gosto de certa época. A cidade é cultura, criação, não só pelo que fazemos nela e dela, pelo que criamos nela e com ela, mas também é cultura pela própria mirada estética ou de espanto, gratuita que lhe damos. A Cidade somos nós e nós somos a Cidade (FREIRE, 2001, p. 22-23).
\end{abstract}

Em nossa leitura, ao encontro do que Freire afirmou na passagem anterior, Cunha (2013) salienta que a cidade é um convite para que a escola estenda seu currículo em direção à realidade, ocupando-a, caminhando por ela, apreciando seu traçado, pulando suas valas, respirando suas casas, suas praças, seus museus, seus bares, esquivando seus imprescindíveis automóveis, percebendo a cidade e o entorno como patrimônio cultural e curricular, em um dado espaço e tempo. Esse autor ainda explicita que uma das principais indisposições de jovens para o currículo escolar é o caráter rotineiro e previsível das salas de aula e das escolas. Para o autor, o currículo escolar deve possibilitar a surpresa, o inesperado, um ambiente escolar em que o "[...] cadeado seja aberto rotineiramente, para deixar sair e entrar o mundo" (CUNHA, 2013, p. 64).

Dentre as práticas educativas do CC Ecossistemas da Terra que consideramos pertinentes ao princípio da contextualização, apresentamos as unidades de significados escritas em resposta à provocação de pensar, desenvolver o senso crítico sobre a importância do estudo sobre os ecossistemas da Terra na constituição do professor:

E por isso é importante aprender para poder ensinar o papel das relações humanas com os outros ecossistemas, ensinar ecossistemas da terra é ensinar ecologia, desenvolver um senso crítico de preservação e saber como nos constituímos dentro de um planeta, um único ecossistema (RE4.2).

Conhecendo os meios que nos cercam temos maior capacidade de entender e, assim, preservar esses ecossistemas (RE4.4).

Para Freire (2011), só é possível ensinar aquilo que se aprende. Por sermos humanos, temos capacidades de aprender sobre, construindo conceitos e modificando nosso meio de acordo com aquilo que aprendemos. Quando temos a compreensão dos contextos que nos cercam, como dos ecossistemas apresentados nas supracitadas unidades de significados, temos a possibilidade de relacionar, de forma crítica, os conteúdos específicos com a realidade, como expõem Delizoicov, Angotti e Pernambuco:

[...] situações reais que os alunos conhecem e presenciam e que estão envolvidas nos temas, embora também exijam, para interpretá-las, a introdução dos conhecimentos contidos nas teorias científicas. Organiza-se esse momento de tal modo que os alunos sejam desafiados a expor o que estão pensando sobre as situações. [...] A meta é problematizar o conhecimento que os alunos vão expondo, de modo geral, com base em poucas questões propostas relativas ao tema e às situações significativas (DELIZOICOV; ANGOTTI; PERNAMBUCO, 2004, p. 200). 
Também no CC Som, Imagem e Informação foi possibilitado o desenvolvimento de uma miniaula, em que um grupo de acadêmicos assumiu o papel de professores de Ciências da Natureza, perpassando as áreas do conhecimento específico (Química, Física ou Biologia). Os graduandos escolheram uma temática central para ser abordada de forma interdisciplinar e contextualizada. Com a realização da atividade, foi produzido o relatório analisado nesta pesquisa, trazido em parte na unidade de significado a seguir:

Trabalhar dentro da perspectiva da contextualização requer que o professor identifique estratégias didáticas capazes de relacionar o conteúdo do currículo com a realidade dos educandos. Sabemos que uma situação contextualizada, para que seja bem explicada, requer uma interação entre diferentes disciplinas, ou seja, pressupõe um trabalho interdisciplinar (RE11.1).

Reportamo-nos às ideias de Freire, quando o autor afirma que não se aprende diferentes saberes dentro de categorias isoladas, conhecendo objetos isolados, mas antes será preciso situar os saberes em seu contexto para melhor conhecê-los. Esses conhecimentos são produtos da relação dos aprendentes com o meio em que estão inseridos, e os objetos de estudo são compreendidos na contextualização das situações. É preciso respeitar a leitura de mundo do educando, o que significa considerar a sua compreensão " $[\ldots]$ como ponto de partida para a compreensão do papel da curiosidade, de modo geral, e da humana, de modo especial, como um dos impulsos fundantes da produção do conhecimento" (FREIRE, 2002, p. 77).

A proposição da atividade de realização de uma miniaula promoveu o estabelecimento de relações dialógicas entre os futuros professores, pois "é preciso ensinar métodos que permitam estabelecer as relações recíprocas entre as partes e o todo em um mundo complexo" (MORIN, 2000, p. 14). Assim, em diferentes momentos da formação inicial de professores, é preciso oportunizar tempos e espaços para a construção de saberes pertinentes às abordagens de conteúdos, possibilitando a construção do conhecimento sobre os processos pedagógicos de forma interdisciplinar e contextualizada.

A unidade de significado que trazemos na sequência foi do CC Diversidade Vegetal II, a partir da produção de exsicatas confeccionadas seguindo os processos de coleta, prensagem, secagem e catalogação dos espécimes vegetais coletados. Após a confecção, foi socializada a produção textual de cada acadêmico sobre o desenvolvimento da atividade, que revelou as aprendizagens e as contribuições para o ensino dos conteúdos pertinente ao estudo da Botânica. Uma das unidades de significado desse CC está expressa a seguir:

\footnotetext{
A exsicata torna-se uma possibilidade de superar determinadas dificuldades encontradas no ensino de botânica, ampliando o saber científico, acerca das espécies que compõem a flora onde os alunos estão inseridos, tornando o conhecimento contextualizado. Estas habilidades são esperadas de um/a profissional que busque contextualizar suas aulas, tornando-as mais expressivas e que atendam às exigências e ultrapasse as dificuldades encontradas no ensino de botânica (RE9.3).
}

A produção das exsicatas possibilitou o desenvolvimento de uma prática contextualizada na medida em que as plantas escolhidas para a realização da atividade deveriam ser do contexto dos futuros docentes e, ao serem coletadas, deveriam ser analisadas as condições dos locais em que as plantas estavam. Logo, essa atividade promoveu uma situação de inserção 

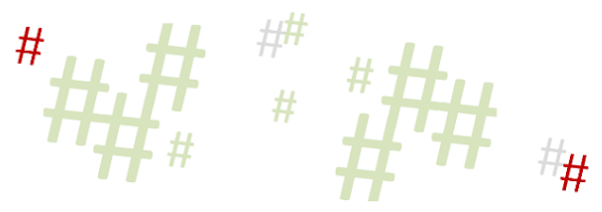

e percepção da realidade não como seu resultado final, mas com parte de um processo que integra um CC e leva a uma problematização do social como parte da construção do conhecimento científico. Junto dos saberes construídos na pesquisa de catalogação das espécies vegetais, um dos objetivos foi buscar informações sobre os saberes populares, sendo que a compreensão acerca do tema em questão parte desse contexto. Freire (2001) afirma que, quando não consideramos os saberes prévios, se está supervalorizando o saber das ciências e que, dessa forma, seria um risco para a compreensão e significação do estudo.

Concordamos também com Bueno (2007, p. 12) quando afirma que: "A contextualização da educação não prescinde dos conteúdos tradicionais selecionados como pertinentes para que um cidadão ou uma cidadã possa buscar compreender o mundo". Assim, para que o ensino de Botânica seja concebido em uma perspectiva contextualizada, devemos considerar a realidade a partir das relações do ser humano com a natureza, resultantes de estar com ela e de estar nela, criando-a e recriando-a, sendo capaz de dominar a realidade em que está inserido, humanizando-a. Freire, ao teorizar sobre a relação do ser humano com a natureza, dirá, ainda, que este vai acrescentando a ela algo de que ele mesmo é o fazedor, o que consiste na capacidade de temporalizar os espaços geográficos, fazendo cultura. Nesse processo, devem ser consideradas as relações do homem (enquanto ser humano) com o mundo e do homem com os outros homens (FREIRE, 1978; 2011).

A atividade proposta no CC Educação Ambiental compreendia a elaboração de um projeto de intervenção aplicável. A proposição e o desenvolvimento dessa prática pedagógica oportunizou a criação e o desenvolvimento de espaço de construção crítica do conhecimento em educação e gestão ambiental, através de discussões de referenciais teóricos e de ordenamentos legais da área, visando à efetiva participação dos acadêmicos, por meio do desenvolvimento de um projeto de ação ambiental (PPC, 2013, p. 188).

Nesse sentido, a unidade de significado que se apresenta na sequência é referente a um projeto que foi escrito para reconhecer a realidade das escolas a partir do diagnóstico do entorno como primeiro passo para o desenvolvimento de um trabalho contextualizado. Também expressa atitude e capacidade de apropriação das teorias estudadas durante a formação:

\footnotetext{
Entende-se que ao estudarmos a realidade, como o ambiente que nos cerca, compreendendo seus problemas, estamos criando a possibilidade de superá-los, e a escola se torna uma instituição com o potencial de transformação da realidade. Esta compreensão da realidade deve acontecer de forma coletiva, em que todos os envolvidos no processo de ensino-aprendizagem participem do estudo; nesse sentido, este projeto apresenta uma possibilidade de qualificação do currículo escolar, a partir da relação do estudo da realidade com o desenvolvimento das práticas educativas escolares. Esta relação deve considerar os aspectos socioambientais para nortear e subsidiar o planejamento e a prática das atividades, permeando de forma mais ampla a gestão da escola, bem como a relação direta com os conteúdos específicos das diferentes áreas do conhecimento (RE13.1).
}

O contexto das escolas é complexo, pois os fatores socioeconômicos e socioambientais dessas instâncias atribuem à estrutura escolar diversas dificuldades, como a própria escassez de recursos e investimento, o que impede - e até impossibilita- a realização de atividades diversificadas que agreguem valor à Educação Básica. Freire (2001, p. 27) afirma que, enquanto educadores preocupados com a humanização, não é possível que se pense "[...] os procedimentos didáticos e os conteúdos a serem ensinados aos grupos populares. Os próprios conteúdos a serem ensinados não podem ser totalmente estranhos àquela cotidianidade”. Caso 
contrário, esses conteúdos acabam sendo pobres de significados e distantes da compreensão significativa que os estudantes constroem da sua realidade.

Quando abordamos a contextualização, estamos oportunizando espaços de construção da educação em uma perspectiva transformadora, formando sujeitos capazes de voltarem-se sobre a realidade de forma dialética - estando, portanto, em conformidade com as Diretrizes Curriculares Nacionais para a Educação Básica, no sentido de superar uma educação que reproduza as injustiças sociais. Entre outras proposições, essas normativas legais preconizam que "[...] a educação brasileira deve assumir o desafio de propor uma escola emancipadora e libertadora" (BRASIL, 2010, p. 13).

Os registros escritos, dos quais foram retiradas as unidades de significados, possibilitaram uma análise ampla das práticas educativas que promoveram a reflexão sobre a formação docente e, nesse sentido, constituíram o professor pesquisador.

Na sequência, são apresentadas as conclusões e perspectivas resultantes da construção deste trabalho.

\section{Reflexões finais}

Retomamos o objetivo deste trabalho de investigar evidências dos princípios da interdisciplinaridade e da contextualização em registros escritos produzidos durante a formação inicial de um professor licenciado em Ciências da Natureza. A partir do exposto e diante da constatação de que os princípios interdisciplinaridade e contextualização, articulados à pedagogia freireana, estavam presentes em registros produzidos durante a formação inicial de um professor de Ciências da Natureza, concluímos que esses contribuíram para o entendimento da sua indissociabilidade na constituição docente do professor pesquisador.

Ao investigarmos o princípio da interdisciplinaridade, fomos capazes de refletir sobre a formação docente em Ciências da Natureza, presente no processo formativo. Destacamos a percepção do potencial interdisciplinar nas abordagens dentro dos $\mathrm{CC}$ do curso de Ciências da Natureza, as quais promoveram posturas/atitudes interdisciplinares do professor pesquisador. Concluímos, assim, que a formação de professores a partir de saberes interdisciplinares opõese à formação tradicionalmente estabelecida de forma curricular fragmentada e antidialógica. Dessa forma, afirmamos que não basta que os currículos sejam formulados, de forma integrada, por área do conhecimento - como no caso do curso de Ciências da Natureza. É importante que o princípio da interdisciplinaridade seja vivenciado em práticas educativas.

Sobre o princípio da contextualização, os resultados e as discussões permitiram concluir que os professores em formação necessitam experienciar práticas educativas que promovam a sua inserção na realidade das escolas. Entendemos que não basta apenas que relações com o contexto sejam estabelecidas, sendo fundamental que se favoreçam reflexões críticas com vivências na realidade. Inferimos, assim, que o contexto das escolas pode ser visto como parte integrante do currículo escolar e dos cursos de formação de professores, bem como que os conteúdos estudados podem permitir a problematização das contradições das situações e dos fenômenos estudados. Assim, os saberes construídos pelos sujeitos envolvidos no processo de ensino-aprendizagem ganharão sentido não apenas como forma de aproximar abordagens em sala de aula, mas para desvelar e decodificar as situações para transformar a realidade.

Com base nas informações analisadas, somos capazes de definir a interdisciplinaridade como a inter-relação e integração de conteúdos específicos dos $\mathrm{CC}$, de métodos de ensinoaprendizagem e de sujeitos que ocupam os espaços do processo educativo e que estejam 
predispostos a estabelecer uma leitura das situações, em sua totalidade, com vistas à garantia da aprendizagem de todos. Os resultados da pesquisa ainda nos permitem apontar o entendimento do princípio da contextualização como a construção de abordagens que partam e se voltem sobre o contexto em que a escola está inserida de forma dialética, a fim de construir sentidos das aprendizagens construídas.

Por fim, salientamos os limites e as possibilidades do estudo, no sentido de que outras pesquisas podem se desdobrar sobre a formação de professores em Ciências da Natureza, para que se compreenda de forma mais complexa a influência dos princípios de interdisciplinaridade e contextualização na constituição dos docentes. Assim, faz-se necessária a realização de investigação com outros egressos, a fim de que seja analisado de que forma as práticas educativas, vivenciadas no decorrer do Curso, foram significativas para a transformação desses sujeitos e da sua prática docente, caso estejam atuando.

De uma forma mais extensa, é interessante que sejam investigadas as práticas educativas de professores que atuem na educação básica, percebendo como esses princípios pedagógicos estão presentes em suas ações. Apontamos, ainda, como possibilidade, a investigação dos princípios discutidos neste texto nas práticas educativas dos docentes do curso de Ciências da Natureza, haja vista que serão a partir destas que outros professores serão formados.

\section{Referências}

BRASIL. Ministério de Educação. Conselho Nacional de Educação. Câmara de Educação Básica. Resolução no 4/2010: Define Diretrizes Curriculares Nacionais Gerais para Educação Básica. Brasília: CNE, 13 jul. de 2010.

BUENO, R. J. Caderno Multidisciplinar: Educação e contexto do Semiárido Brasileiro. Currículo, contextualização e complexidade: Elementos para pensar a escola no Semiárido Ano 2, No 04, dezembro de 2007. Bahia: Juazeiro: Selo Editorial RESAB, 2007.

CHIZZOTTI, A. Pesquisa qualitativa em ciências humanas e sociais. Petrópolis: Vozes, 2006.

CUNHA, A. L. A. da. Corpo-ambiente-cultura na formação de professores/as. In: SILVEIRA, M. I. C. M. da. BIANCHI, P. (org.). Núcleo Interdisciplinar de Educação. Articulação de contextos \& saberes nos (per)cursos de licenciatura da Unipampa. Tribo da Ilha. Florianópolis, 2013. p. 53-65.

DELIZOICOV, D.; ANGOTI, J. A.; PERNAMBUCO, M. M. Ensino de Ciências: Fundamentos e métodos. São Paulo: Cortez, 2004.

FAZENDA, I. Integração e interdisciplinaridade no ensino brasileiro: efetividade ou ideologia. São Paulo, Loyola, 1979.

FAZENDA, I. Práticas interdisciplinares na escola. São Paulo: Cortez, 1991.

FAZENDA, I. O que é interdisciplinaridade? São Paulo: Cortez, 2008. 
FRANCO, M. L. P. B. "Estudo de caso", no falso conflito entre "pesquisa qualitativa" e "pesquisa quantitativa". Inter-Ação, v. 14/15, n. 1-2, p. 1-6, jan./dez., 1990/91. Disponível em: http://cienciaparaeducacao.org/eng/publicacao/franco-m-l-p-b-o-estudo-de-caso-no-falso -conflito-que-se-estabelece-entre-pesquisa-qualitativa-e-pesquisa-quantitativa-cadernos-doprograma-de-psicologia-educacional-pucsao-paulo-n-7-p-32/. Acesso em: 2 set. 2019.

FREIRE, P. A mensagem de Paulo Freire: textos de Paulo Freire selecionados pelo INODEP. São Paulo, Nova Crítica, 1977.

FREIRE, P. Educação como Prática da Liberdade. 8. ed. Rio de Janeiro: Paz e Terra, 1978.

FREIRE, P. Política e Educação: ensaio. 6 ed. São Paulo: Cortez, 2001.

FREIRE, P. Pedagogia da autonomia: saberes necessários à prática educativa. 21 ed. São Paulo. Editora: Paz e Terra, 2002.

FREIRE, P. Pedagogia do Oprimido. 50 ed. Rio de Janeiro: Paz e Terra, 2011.

GADOTTI, M. Interdisciplinaridade: atitude e método. São Paulo: Instituto Paulo Freire, 2004.

JAPIASSU, H. Interdisciplinaridade e patologia do saber. Rio de Janeiro, Imago, 1976.

MORAES, R. GALIAZZI, M. C. Análise Textual Discursiva. 2 ed. Ijuí: Editora da Unijuí, 2013.

MORIN, E. Os sete saberes necessários à educação do futuro. São Paulo: Cortez, 2000.

MORIN, E. Educação e complexidade: os sete saberes e outros ensaios. São Paulo: Cortez, 2005.

PEREZ GOMEZ, A. La cultura escolar en la sociedad neoliberal. Madrid: Morata, 1999.

PPC. Projeto Pedagógico do Curso de Ciências da Natureza. UNIVERSIDADE

FEDERAL DO PAMPA, Uruguaiana, 2014. Disponível em: http://cursos.unipampa.edu.br /cursos/cienciasdanatureza/files/2011/05/PPC-Ci\%C3\%AAncias-Natureza.pdf. Acesso em: 5 ago. 2019.

SANTOMÉ, J. T. Globalização e interdisciplinaridade: o currículo integrado. Porto Alegre: Artmed, 1998.

Recebido em setembro de 2019.

Aprovado em maio de 2020. 